\title{
TESES E DISSERTACÕES EM ANTROPOLOGIA DEFENDIDAS NA UNIVERSIDADE FEDERAL DO RIO GRANDE DO SUL NO PERÍODO DE JULHO DE 2003 A OUTUBRO DE 2003
}

TESE

\section{MENASCHE, Renata}

Orientadora: Maria Eunice Maciel

Os grãos da discórdia e o risco à mesa: um estudo antropológico das representacooes sociais sobre cultivos e alimentos transgênicos no Rio Grande do Sul.

Este estudo pretende analisar as representações sociais de consumidores e agricultores gaúchos a respeito de alimentos e cultivos geneticamente modificados. As visões e comportamentos de consumidores e agricultores observados são interrogados a partir de perspectivas que se propõem a apreender suas percepções de risco, suas representações referentes à alimentação e suas interpretações e estratégias diante de uma das dimensões presentes no debate sobre o tema, a política, a partir da qual seria constituída a legitimidade das lavouras transgênicas ilegais. As noções de medo e risco se evidenciariam centrais para a reflexão. Os dados analisados neste trabalho foram obtidos através de pesquisa etnográfica desenvolvida junto a agricultores de duas distintas regiões rurais do Rio Grande do Sul e de entrevistas em profundidade realizadas junto a moradores de Porto Alegre. 


\section{DISSERTACÃO}

\section{GOMES, Alessandro Garcia}

Orientadora: Claudia Lee Williams da Fonseca

\section{0 processo de manipulacão de identidades em uma comunidade a partir de um projeto de intervenção institucional.}

Este trabalho tem como foco de pesquisa uma comunidade da cidade de Figueiras, litoral norte do Estado do Rio Grande do Sul, onde foi realizado o projeto institucional Remanescentes de Quilombos, o qual tem por finalidade proporcionar aos moradores locais a reivindicação de terras como quilombolas. Analisa as categorias identitárias percebidas a partir das classificações definidas pelo grupo pesquisado levando em conta, além do estímulo do projeto, as "memórias" que remontam ao passado do grupo e o modo como as referências coletivas são manipuladas na construção do presente. Problematiza a questão da "identidade", percebida como um processo, enfatizando seu caráter dinâmico e, portanto, sujeito a influências de cunho situacional e contextual. Define os principais grupos representativos desta realidade a partir do referencial étnico e relativiza o alcance das categorias identitárias envolvidas nesse processo, apresentando a diversidade de possibilidades classificatórias observadas em decorrência da definição do grupo pesquisado e a relação entre elas. 